\title{
Laboreal
}

Volume $4 \mathrm{~N}^{\circ} 2$ | 2008

A inovação

\section{Argumentos para uma abordagem dialógica da inovação}

Argumentos para un planteamiento dialógico de la innovación

Arguments pour une approche dialogique de l'innovation

Arguments to a dialogic approach to innovation

\section{Pascal Béguin}

Tradutor. Francisco Moura Duarte

\section{OpenEdition}

\section{Journals}

\section{Edição electrónica}

URL: http://journals.openedition.org/laboreal/11392

DOI: 10.4000/laboreal. 11392

ISSN: 1646-5237

\section{Editora}

Universidade do Porto

\section{Refêrencia eletrónica}

Pascal Béguin, « Argumentos para uma abordagem dialógica da inovação », Laboreal [Online], Volume $4 \mathrm{~N}^{0} 2$ | 2008, posto online no dia 01 dezembro 2008, consultado o 10 outubro 2019. URL : http:// journals.openedition.org/laboreal/11392 ; DOI : 10.4000/laboreal.11392

\section{Este documento foi criado de forma automática no dia 10 outubro 2019.}



Laboreal está licenciado com uma Licença Creative Commons - Atribuição-NãoComercial 4.0 Internacional. 


\section{Argumentos para uma abordagem dialógica da inovação}

Argumentos para un planteamiento dialógico de la innovación

Arguments pour une approche dialogique de l'innovation

Arguments to a dialogic approach to innovation

Pascal Béguin

Tradução : Francisco Moura Duarte

\section{NOTA DO EDITOR}

Manuscrito recebido em : Setembro/2008

Aceite após peritagem em : Novembro/2008

\section{Introdução}

1 Quando se interessa pela concepção de artefatos, a temática da inovação aparece como preciosa para aqueles que têm como preocupação melhor considerar o ponto de vista $\mathrm{e}$ as ações daqueles que trabalham e vivenciam este processo.

2 Falar de inovação é, de fato, desenhar um processo criativo em situação, durante o qual a novidade técnica, oriunda do meio da pesquisa ou dos escritórios de projeto, será submetida ao movimento na atividade daqueles que a utilizam, gerando uma mudança concreta. Tal temática é, evidentemente, muito ampla e investigada por um conjunto de disciplinas. Para as "Science and innovation policy studies" próxima da economia, da gestão e das ciências políticas, a temática da inovação estuda as relações entre a novidade técnica e sua evolução sob a influência do mercado. Para as "Sciences, Technology and society studies" mais próximas da sociologia, da história ou da antropologia, são as ligações entre a novidade técnica e os contextos culturais ou sociais que constituem o foco. A ergonomia se interessa pelas relações entre a 
concepção dos sistemas de trabalho e as atividades profissionais. Considerando a "inteligência" dos trabalhadores como uma marca essencial da atividade de trabalho (Montmollin, 1992) ; evidenciando a inventividade dos operadores em situação (Weill Fassina, Rabardel \& Dubois, 1993[1]) e afirmando que a "concepção continua no uso" (Béguin, 1993), a ergonomia da atividade se inscreve nesta temática. A atividade é fonte de criatividade situada, que explora, interpreta e reorganiza os dados e as decisões ao longo de seu desenvolvimento (Béguin \& Clot, 2004).

Ora deste ponto de vista, os processos de concepção aparecem bastante problemáticos. Midler (1993) mostrou de maneira convincente que as formas atuais de condução dos projetos podem ser modelas como processos onde se considera que "no início não se sabe nada" e onde "no final tudo já está decidido". A necessidade de "partir do nada" é, inclusive, fortemente teorizada como, por exemplo, na abordagem da re-engenharia (Hammer \& Champy, 1993) na qual é desenvolvida a estratégia do "Clean Slate Design", ou seja, de retomar as coisas a partir do zero. Quanto à idéia segundo a qual "tudo já está decidido no final", ela já foi defendida em 1932 nos dizeres da exposição universal de Chicago : "a ciência descobre, a indústria aplica e o homem se submete". Isto é fazer pouco caso das racionalidades, dos valores próprios àqueles que, num determinado meio, colocam em ação um objeto ou um procedimento concebido. Na realidade, os trabalhadores sabem muito coisa antes e, para eles, tudo começa após.

O objetivo desse artigo é fazer algumas proposições para uma "concepção inovadora", ou seja, para uma abordagem de concepção que articula a inventividade dos operadores e a inventividade dos projetistas. Num primeiro momento, será retomada a idéia segunda a qual a concepção continua durante o uso. Sobre esta base, será argumentado o interesse de apreender a concepção como um processo dialógico. Num terceiro tempo, serão discutidas e ilustradas as formas que essa abordagem pode tomar nas diferentes etapas do processo de concepção.

\section{A concepção continua durante o uso}

5 Dizer que "a concepção continua durante o uso" é uma fórmula heurística, mas imprecisa. O fato dos operadores não utilizarem os dispositivos técnicos como se poderia esperar e que eles os modificam momentaneamente ou permanentemente pode ter diversas origens. Podem-se distinguir três, que designam igualmente diferentes contribuições da ergonomia para a concepção. (Béguin, 2007b).

\subsection{A cristalização}

Uma primeira razão pela qual os trabalhadores podem modificar os artefatos vem do fato dos projetistas não considerarem suficientemente o seu funcionamento e sua atividade. Na concepção, a necessidade de antecipar a atividade é incontornável na medida em que todo dispositivo técnico, todo artefato "cristaliza" um conhecimento, uma representação e, num sentido mais amplo, um modelo de usuário, de sua atividade e de seu trabalho (Léontiev, 1976; Simondon, 1958). Mas uma vez cristalizado no artefato, este modelo é veiculado numa situação de trabalho, com o risco de ser fonte de numerosas dificuldades si estes modelos são falsos ou incompletos. Por exemplo, prever escadas para ter acesso a determinados locais repousa sobre a representação de que não haverá pessoas deficientes. Da mesma forma, um sistema informático, um 
software mobiliza um modelo psicológico do usuário (Caroll, 1991). Modelo que pode repousar sobre o postulado da ignorância do operador (Bannon, 1986) ou ao contrário, lhe conferir performances excepcionais. Para conceber uma mesa de trabalho, a redução antropométrica não é pertinente. Esses dados veiculam implicitamente a cultura ocidental : a mesa não será adaptada a meios culturais onde se sentam no chão (Wisner, 1972). Pode-se fazer a seguinte hipótese : os modelos susceptíveis de serem manipulados pelos projetistas e que são cristalizados nos artefatos devem considerar o conjunto de dimensões humanas : da fisiologia ao cultural.

7 Ora, numerosas análises mostraram que os modelos do homem ou da atividade que são mobilizados pelos projetistas podem apresentar lacunas e, até mesmo, serem completamente errados (Wisner, 1972 ; Daniellou, 1992 ; Daniellou \& Garrigou, 1993). A contribuição da ergonomia reside, portanto, no fato de sua capacidade de enriquecer e, mesmo, a transformar estas representações e modelos implícitos que os projetistas mobilizam sobre o trabalho e os trabalhadores. Para construir modelos melhor orientados, os saberes disciplinares oriundos da psicologia e da fisiologia são essenciais. Mas eles não são suficientes. A identificação das características da audição humana não permite, por exemplo, saber que o ruído da usinagem é um índice de primeiro plano para o mecânico que realiza a manutenção. Ora se a regulagem da máquina for realizada sem considerar este fato, ela poderá ser feita com a tampa de proteção aberta, colocando em risco a saúde desse mecânico. Para produzir representações do trabalho atual e futuro, o ergonomista deve, portanto, utilizar abordagens de análise do trabalho (Guérin, Laville, Daniellou, Durafourg \& Kerguelen, 1997) ou de simulação (Béguin \& Weill-Fassina, 1997) cuja finalidade é produzir modelos bem adaptados à realidade e à singularidade de uma dada situação de trabalho.

\subsection{A Plasticidade}

8 Uma segunda origem da inventividade dos operadores, claramente inscrita na abordagem da ação situada[ $\left.{ }^{2}\right]$, postula que a inventividade dos operadores é oriunda da singularidade das situações e dos contextos da ação. As situações de trabalho podem variar consideravelmente: desregulagens de ferramentas, instabilidade da matéria prima, falta de um colega etc. (Garrigou, Thibault, Jackson, \& Mascia, 2001). Além disso, existe uma diversidade de pessoas e uma variabilidade no tempo para uma mesma pessoa : flutuação em curto prazo (variação do estado funcional, por exemplo, pela fadiga) e em longo prazo (envelhecimento) (Daniellou, Laville \& Teiger, 1983). Durante seu trabalho, os operadores encontram imprevistos e resistências ligadas às contingências da situação e às flutuações de seu próprio estado. Ora face às contingências das situações, face aos eventos, a operação das instalações supõe uma "inteligência da tarefa" (Montmollin, 1992), uma criatividade situada ou uma “improvisação criativa” (Rasmussen, 2000).

9 Na abordagem anterior (cristalização), o objetivo era modelar a atividade a fim de especificar artefatos ou sistemas técnicos. Esta segunda abordagem mostra os limites dessa estratégia : as modelagens que serão realizadas durante o processo de concepção serão forçosamente limitadas. A realidade do trabalho sempre ultrapassa o modelo que é construído. Deste fato, decorre a necessidade de se especificar margens de manobra, conceber sistemas "plásticos" para que a atividade em situação tenha graus de liberdade e de autonomia para tornar o sistema técnico mais eficiente, tanto no plano 
da produção, quanto no plano da saúde dos operadores. Daniellou (2007) dá um exemplo didático dessa abordagem no caso de uma situação de informatização. Quando se possui uma impressora, pode-se recorrer à impressão quando necessário. Mas sem a impressora, a única possibilidade é recorrer à tela ou ao monitor de vídeo. A primeira solução (impressora e monitor de vídeo) é preferível, pois ela oferece maiores "margens de manobra" para os operadores.

10 A concepção de um sistema plástico é uma orientação de pesquisa importante e antiga nos trabalhos que fazem referência às correntes teóricas da cognição e da ação situada. Quais são as características que devem apresentar um sistema técnico para que ele seja plástico? Gerson e Star (1986) deixaram de lado as bases de tal programa, argumentando que a finalidade é conceber sistemas sócio-técnicos que reavaliam constantemente seu próprio funcionamento e que se reestruturam em função das circunstâncias. Trata-se de "conceber para um uso indeterminado" (Robinson, 1993).

\subsection{O Desenvolvimento da Atividade}

11 Apesar de suas diferenças, as duas abordagens precedentes compartilham a mesma hipótese : a inventividade dos operadores em situação é devido às causas externas à atividade. No primeiro caso, porque se postula que as representações dos projetistas são insuficientes. No segundo caso, porque a criatividade é situada na contingência local e condicionada pelo evento. Essas interpretações não são falsas, mas, ainda são insuficientes. A inventividade dos operadores em situação, também, tem por origem fontes intrínsecas à sua atividade. Sublinharemos três idéias neste sentido. A primeira idéia é bem estabelecida pela sociologia da inovação e pela antropologia das técnicas (Geslin, 1999; Perrin, 1983) : não existe vazio técnico (técnica compreendida pelos saberes eficazes). Na realidade, todo artefato (máquina, ferramenta ou processo de produção) é operado por trabalhadores. Para que um artefato ou processo produtivo seja utilizado ou operado são necessárias, maneiras de fazer e de agir, formas de pensar, conceitos operativos, competências e valores que permitem ou que são associados a essa utilização. Segunda idéia : essas maneiras de fazer e de agir podem ser qualificadas como "normas antecedentes" (Schwartz, 2000), na medida em que elas serão, freqüentemente, colocadas em movimento pela novidade técnica. Coloca-se, portanto, a questão da apropriação do novo pelos operadores e sua gênese. Quando se analisa essas gêneses, processos pelos quais os operadores se apropriam de uma novidade técnica e a constituem como recurso para suas ações, pode-se constatar que elas revelam duas formas distintas : ou o operador desenvolve novas técnicas a partir daquelas que ele dispõe ou ele adapta, modifica, transforma os dispositivos para conformá-lo às suas próprias construções. Este é um dos principais resultados dos trabalhos realizados sobre as "gêneses instrumentais". Observa-se, durante esses processos, uma instrumentação e/ou uma instrumentalização. Por instrumentação, entende-se um processo de acomodação: um processo de especificação, de enriquecimento ou de conformação das maneiras de fazer e de pensar. Os fornos de microondas, por exemplo, geraram processos de instrumentação : certos tipos de prato não podem ser utilizados. A instrumentalização é uma "assimilação" do artefato às normas antecedentes, osoperadoresadaptam, modificam, re-interpretam, até mesmo transformam (temporariamente ou permanentemente) os dispositivos para conformá-los às suas próprias maneiras de pensar e de agir. Os processos de instrumentalização são processos durante o qual o operador atribui ao objeto técnico uma função distinta 
daquela prevista pelo projetista. Utilizar uma chave de inglesa como martelo é um exemplo elementar de instrumentalização. Nas situações de trabalho, trata-se evidentemente de processos de maior amplitude articulando processos de instrumentação e de instrumentalização se desenvolvendo durante longos períodos de tempo. Nesse sentido, é que se prefere falar de "gêneses instrumentais" (ver Rabardel \& Béguin, 2005).

12 As gêneses instrumentais (e particularmente a instrumentalização) constitui uma terceira fonte de inventividade dos operadores. Face à novidade, esses últimos podem fazer evoluir as formas de suas ações, mas eles podem, também atribuir ao artefato uma função que não estava prevista pelos projetistas. Esta terceira interpretação da inventividade abre novos caminhos de ação sobre a concepção. A introdução de uma novidade técnica, numa dada situação, permite resolver antigos problemas, mas ela modifica a natureza da tarefa e cria novos problemas para os quais novas formas de ação serão necessárias (ver Ellul, 1977 ; Cole, 1996). Fica evidente, portanto a questão dos desenvolvimentos possíveis ou impossíveis da atividade e não somente do desenvolvimento da novidade técnica.

\section{Uma abordagem dialógica da concepção}

13 As orientações que acabam de ser apresentadas apresentam numerosas diferenças, em particular, porque elas se apóiam sobre orientações teóricas e epistemológicas distintas. Da abordagem modeladora (cristalização) passou-se para uma abordagem muito próxima da cognição e ação situadas (plasticidade) e, posteriormente, para trabalhos centrados sobre a antropologia das técnicas e a psicologia cultural (desenvolvimento). Apesar de suas diversidades, essas posições avançam argumentos que estão longe de serem incompatíveis. Coloca-se, então, a seguinte hipótese : elas definem uma gama de ações a serem usadas no interior de um processo de concepção. Como será argumentado, um modelo dialógico da concepção permite articular essas diferentes orientações.

\subsection{Uma concepção conjunta de artefatos e de atividades}

Um dos ensinamentos que se pode tirar da análise prévia do uso para a concepção é a necessidade de se apreender simultaneamente as características dos sistemas técnicos de uma parte e a atividade dos operadores de outra parte. Na realidade, a "cristalização" enfatiza que a atividade de trabalho deve ser modelada ao mesmo tempo em que se especificam as ferramentas. A "plasticidade" argumenta que a eficiência dos dispositivos não repousa unicamente sobre as decisões oriundas dos escritórios de projeto, mas também da atividade em situação. O "desenvolvimento", por sua vez, indica que a atividade se desenvolve em conjunto com o desenvolvimento da ferramenta. É na realidade, a organização sistêmica dessas duas entidades que constitui o objeto que se está concebendo [ $\left.{ }^{3}\right]$.

15 A abordagem instrumental, já mencionada, insistiu particularmente sobre este ponto, afirmando a necessidade de se fazer ma distinção entre "artefato" e "instrumento". o artefato é um objeto fabricado em suas dimensões materiais ou simbólicas. O instrumento é uma entidade composta que compreende de um lado o artefato e, também, um componente ligado à ação. É a associação dessas duas dimensões, 
organizadas num sistema, que forma o instrumento. Por exemplo, uma caneta é um artefato que não se constitui num instrumento em si mesmo. Para que seja um instrumento, é necessário que ela seja associada a formas organizadas da ação (que são, inclusive objeto de uma longa aprendizagem para as crianças). É essa associação que permite a escrita. $\mathrm{O}$ instrumento pode, portanto, ser definido como uma entidade bipolar que associa dois elementos (Béguin \& Rabardel, 2000 ; Rabardel \& Béguin, 2005). Uma face humana, que vem do sujeito (o trabalhador, o utilizador) e uma face artefactual (um artefato, uma parte de um artefato ou um sistema de artefatos) de natureza material e simbólica.

Um dos interesses dessa conceituação é de argumentar que mesmo quando um artefato é muito bem concebido, instrumento nenhum está finalizado quando ele sai do escritório de projeto. Em todos os casos, o instrumento "vivo", aquele que é efetivamente colocado em uso, supõe que o humano, usuário ou trabalhador, associe a ele uma parte de si mesmo. Ora, ninguém pode substituir este usuário ou este trabalhador [4]. Esta definição do instrumento sugere, portanto que projetistas e usuários contribuam com a concepção sobre a base de suas próprias competências e de suas diversidades. Mas para considerar este fato na concepção é necessário operar uma mudança de unidade de análise.

\subsection{Aprendizagem mútua e diálogo}

17 Acabamos de dizer que um instrumento é um casamento entre construções cognitivas, culturais e sociais que são próprias dos usuários e de uma entidade artefactual. Mas se centrar na concepção é ver que atrás do artefato existe o trabalho do outro (Béguin, 1994). Clot (1999) igualmente aponta: a tarefa é um resultado do trabalho dos projetistas. Dizer que a concepção continua no uso é afirmar que o operador recoloca em movimento, re-interroga o resultado do trabalho dos projetistas. Este deve, portanto, ter um status no esquema conceitual. É necessário, portanto, mudar a unidade de análise : centrar o foco não mais sobre o sujeito e sua tarefa como na abordagem instrumental, mas sobre a dinâmica das trocas que operadores e projetistas efetuam sobre os rascunhos e esboços múltiplos do objeto em curso de concepção. Mas sobre quais bases?

Uma primeira reposta reside na análise das "aprendizagens mútuas". Todo um conjunto de trabalhos de análise da atividade dos projetistas mostra a importância das aprendizagens múltiplas (Bjerknes \& Bratteteig, 1987, 1995; Hatchuel, 1996). O processo de concepção é, na realidade, um processo que se caracteriza por um duplo movimento de diferenciação (existem especializações) e de interdependência: nenhuma decisão pode ser tomada independente de outras decisões. Assim, quando um projetista propõe uma solução, ele pode conduzir os outros atores do processo a fazerem "aprendizagens" nos seus próprios domínios de competência. Mas esses últimos validam ou reformam a solução inicial. Pode-se estender esse esquema para as interações entre projetistas e operadores (Béguin, 2003). Assim, o operador fica susceptível para aprender sobre o trabalho do projetista e de realizar aprendizagens e desenvolver sua atividade. Mas tais aprendizagens são possíveis ou impossíveis, elas validam ou colocam em movimento o resultado do trabalho do projetista. Este pode ser conduzido a realizar novas aprendizagens a partir das aprendizagens realizadas pelo operador. 

propõe um esquema para pensar a articulação dos mesmos. Entretanto, ela considera mal o fato de que é na diversidade que se efetua a concepção (ver Bødker \& Grønboek, 1996, para uma discussão mais profunda sobre esse aspecto). As divergências, os desacordos (e não somente as aprendizagens) são dimensões importantes da concepção (Easterbrook, Beck, Goodlet \& Plowman, 1993). Os processos de concepção são inclusive processos sociais (Bucciarelli, 1994) marcados por diversos conflitos, a ponto de se argumentar que a concepção é um "conflict ridden" (Moran \& Carroll, 1996). É essencial considerar esta "polifonia" no interior do grupo e, também, de considerá-la no plano dos métodos. Um modelo dialógico oferece esta possibilidade [5].

A abordagem dialógica nos diz Bakhtin (1970), é constituída por relações entre uma linguagem interior e uma linguagem exterior. Na realidade, a dinâmica da atividade da linguagem exterior (aquela dos locutores que se respondem) se efetua por intermédio de uma segunda linguagem, a linguagem interior dos protagonistas. Assim, "dans le dialogue, les répliques ouvertes de l'un empiètent sur les répliques du dialogue intérieur de l'autre" (op.cit, p. 347) a palavra é "eqüipolente" ou "bivocal" (op.cit, p. 363), composta de uma parte privada e uma parte pública. Wertsch (1998) resumiu bem esta idéia escrevendo : "Because words is half-ours and half-someone else's [...] one is invited to take the externally word as a "thinking device", or as a starting point for a response that may incorporate and change the form of meaning of what was originally said" (op. cit. p. 67). Tal abordagem parece ter um forte valor heurístico para apreender a concepção de um instrumento, no sentido definido neste texto mais acima [ $\left.{ }^{6}\right]$. Dois pontos nos parecem particularmente importantes.

eira idéia, os diálogos são um motor da concepção. Como a palavra, um instrumento é eqüipolente em dupla face, composto de uma face artefactual que vem do projetista e de uma face humana própria do trabalhador ou do usuário. Ainda, o motor da concepção se situa na diversidade das posições dos atores. A posição de um é uma fonte de discordância ou de contradições para o outro. Mas ela constitui-se igualmente num recurso : ultrapassar essa contradição permite produzir uma resposta nova ou é fonte de novidade. Em outras palavras, o instrumento sem desenvolve na medida do desenvolvimento dos diálogos.

Segundo ponto : uma abordagem dialógica redefine o status do instrumento. Este se desenvolve junto, a partir dos diálogos como já mencionado, mas é, também, o vetor. Encontrase aqui a problemática dos "objetos intermediários" de concepção (Mer, Jantet \& Tichkievitch, 1995). O conceito de objeto intermediário postula que os objetos da concepção veiculam, mas também, "focalizam" as trocas. Assim, por exemplo, a maquete do automóvel é bem adaptada ao estilista que se interessa à forma geral do veículo. Mas ela não coloca em cena a problemática do especialista do produto que se interessa ao "serviço de transporte" que o carro possibilita (Midler, 1993). Essa idéia é compartilhada. Em ergonomia é estratégico que os objetos intermediários contribuam a "focalizar"as trocas sobre o trabalho dos operadores e sobre o desenvolvimento de suas atividades. Mas uma abordagem dialógica adiciona uma dimensão suplementar à do objeto intermediário : as trocas se efetuam sobre a base de "hipóteses instrumentais". 0 objeto intermediário veicula hipóteses que são relativas ao trabalho do outro (e não somente em relação ao objeto em curso de concepção). A análise do trabalho dos projetistas mostra, de fato, que quando se especifica um artefato, um projetista faz hipóteses sobre a função e o uso a ele associado (Nicolas, 2000) [7]. Mas trata-se de uma 
hipótese no sentido de que a produção do projetista pode ser falsa : ela será validada, questionada ou colocada em movimento pela atividade do operador.

\section{Organizar uma concepção dialógica}

Esse modelo dialógico fornece uma visão muito diferente da abordagem clássica da engenharia, na qual a concepção é vista como uma mudança de estado durante a qual os problemas devem trazer uma solução. No dialogismo, a concepção aparece sem início nem fim : trata-se antes de um processo cíclico, no qual o trabalho de um, projetista ou operador, fecunda o trabalho do outro e no qual a última palavra, não é, provavelmente, jamais pronunciada.

Ele abre várias pistas de organização para uma concepção inovadora. Apoiando-se sobre a hipótese instrumental, que acaba de ser introduzida, examinaremos três pistas que se situam em movimentos temporais diferentes.

\subsection{Objetivar as hipóteses instrumentais dos operadores}

Esta primeira via consiste a instituir a atividade dos operadores como uma hipótese instrumental, fonte da atividade do projetista. A atividade do usuário é, portanto, temporalmente primeira. Tomaremos dois exemplos.

O primeiro é oriundo de uma pesquisa sobre os sistemas de CAD - (Computer Aid Design) e sobre o trabalho dos técnicos que os utilizam (Béguin, 1994). A análise do trabalho dos projetistas utilizando o CAD coloca em evidência que um dos elementos mais estruturantes da atividade reside na presença de um esquema de concepção largamente compartilhado entre eles, qualquer que seja a especialidade técnica. Essa organização invariante da ação apresenta-se como um processo cíclico, de duração relativamente breve (da ordem do minuto). Cada ciclo compreende duas fases bem distintas. Durante a primeira fase, o projetista se informa das especificações iniciais e as traduz sob uma forma gráfica. Depois, durante a segunda fase, o projetista avalia sua produção simulando mentalmente o funcionamento de parte do sistema elétrico que ele acaba de desenhar. Esta simulação permite de fazer aparecer certos disfuncionamentos e conduz o projetista a efetuar modificações [ $\left.{ }^{8}\right]$. É possível inclusive mostrar que certos softwares de CAD, que não permitem essa segunda etapa do ciclo, tornam muito difícil e até mesmo impossível, a atividade de concepção. Mas, sobretudo, a apresentação para os projetistas de CAD desse esquema cíclico de organização da atividade permitiu elencar princípios de concepção de um novo software. Mais particularmente, tratava-se de criar novas funções que gerariam diferentes estados de funcionamento do sistema desenhado na tela do computador. Por exemplo, para um software destinado à concepção de sistemas elétricos, tratava-se de simular os fluxos elétricos de acordo com os diferentes estados do circuito elétrico para facilitar a identificação dos disfuncionamentos (Béguin, 1997).

Neste exemplo, a finalidade era instituir o que foi chamado acima de "a face humana" do instrumento para constituí-la em fonte e recurso para a atividade dos projetistas do artefato. Mas nós também vimos que os operadores podem igualmente modificar as características técnicas dos artefatos (a face técnica do instrumento). Essas modificações podem evidentemente ser um recurso para a atividade dos operadores. Será apresentado agora um exemplo sobre a concepção de uma máquina de 
envelopamento. O estudo foi realizado num centro nacional de expedição de documentos administrativos de um ministério (Béguin, Millanvoye \& Cottura, 1998). Ele era consecutivo à chegada de uma nova máquina, inteiramente automatizada e muito mais rápida que as precedentes. Infelizmente será impossível de realizar a produção durante várias semanas. A análise do trabalho permite identificar a causa. Para regular uma máquina de envelopamento, é necessário construir um representação da cinética do papel com a máquina em funcionamento. Era impossível regular a máquina e evitar borrões sem esta possibilidade. A nova máquina, completamente fechada, não permitia essas tomadas de informação, apesar de numerosas informações serem apresentadas nas telas informatizadas. A investigação realizada revelou que as antigas máquinas foram profundamente modificadas. Os operadores haviam modificado as coberturas e portas a fim de instalar janelas que permitissem as tomadas de informações significativas. Essas modificações foram então analisadas e serviram de base para a constituição de especificações para a concepção de uma nova máquina automatizada. Evidentemente, essas hipóteses instrumentais não foram usadas pelos projetistas tais como elas foram escritas. Elas foram apenas um recurso para a atividade de concepção.

Podemos destacar que a objetivação das hipóteses instrumentais dos operadores demanda um trabalho específico da ergonomia que repousa sobre sua capacidade de considerar as incertezas do processo de concepção e o correspondente trabalho dos projetistas. A noção de "ação tipo" (Maline, 1994), por exemplo, parece visar a objetivar as hipóteses instrumentais dos operadores. Mas esta noção supõe que a situação futura seja suficientemente especificada para se poder identificar as hipóteses dos projetistas. Quando não é o caso, torna-se necessário mudar a unidade de análise. Podemos, então, nos centrar sobre as "configurações de uso" (ver Duarte, Lima, Remiro \& Castro Maia, 2008).

\subsection{Conceber as hipóteses instrumentais}

Nesta segunda via, é a atividade do projetista que é, temporalmente, a primeira. Ela consiste a especificar a face artefactual das hipóteses instrumentais, cujas propriedades poderão ser modificadas, posteriormente pelos operadores.

Daremos um exemplo sobre a concepção de um sistema de informática para gestão do correio eletrônico. Trata-se de um software inicialmente concebido como um agente inteligente, uma secretária automática que filtra as mensagens eletrônicas (Malone, Grant \& Turbak, 1986). Mackay (1988) mostrou que os operadores modificam as funções disponibilizadas pelo dispositivo: eles querem ser informados da chegada de uma mensagem e querem poder consultá-las. Os usuários desenvolvem, portanto, novas funcionalidades. Por exemplo, eles utilizam o sistema como uma secretária que arquiva as mensagens em zonas apropriadas e não como filtro. Mas, sobretudo, uma das vantagens desse software é que ele permite a cada operador de constituir seu próprio filtro em função de suas necessidades específicas (de Keyser, 1988).

Os artefatos adaptáveis estão igualmente na origem das dinâmicas evolutivas das formas de ação. Em particular, eles permitem de fazer com que o artefato se encarregue de parte da organização da ação. Assim, temos observado que os projetistas-desenhistas que trabalham com o CAD criam "scripts informáticos" que corresponderiam a tarefas realizadas anteriormente (Rabardel \& Béguin, 1995). Num outro domínio da informática, a constituição de funções complexas (macro-comandos) que permitem a 
combinação de funções elementares em um único comando mais possante repousa sobre o mesmo princípio : ele consiste a delegar ao artefato, uma parte das ações do usuário.

Um dos papéis importantes da ergonomia na concepção de sistemas modificáveis, repousa sobre o fato de não se definir somente as propriedades do artefato mas, também, a atividade correspondente e as condições de seu uso. No plano do artefato, seria necessário especificar diferentes níveis de modificações possíveis para os sistemas (por exemplo, não modificável, modificável e adaptável dentro dos limites e perspectivas vislumbradas pelo projetista, transformáveis em novas perspectivas do ponto de vista das funções) (Henderson \& Kyng, 1991; Randell, 2003). Mas isso demandaria identificar as diferentes práticas correspondentes dos usuários (por exemplo, escolha das opções previamente determinadas durante a concepção inicial, construção de novos comportamentos do artefato a partir de elementos existentes). De outra forma, essas práticas não devem ser unicamente apreendidas no plano do artefato. Modificar os sistemas técnicos demanda recursos. Recursos cognitivos, evidentemente (existência de manual, possibilidades de trocas com os projetistas quando necessário,...). Mas também recursos temporais : tal atividade de concepção continuada em situação de trabalho demanda tempo. É necessário que a organização o permita (e não somente o artefato).

\subsection{Colocar em ressonância as hipóteses instrumentais dos operadores e dos projetistas durante a concepção}

Nas duas primeiras vias descritas acima, a atividade dos projetistas e dos operadores é assíncrona. A terceira via visa a organizar um sincronismo. Ela consiste a colocar em ressonância as hipóteses instrumentais dos projetistas com aquelas dos usuários. $\mathrm{O}$ que é específico nessa terceira via é que as trocas dialógicas entre os projetistas e usuários constituem o motor da concepção como iremos ver num exemplo sobre a concepção de um alarme destinado a prevenir o desencadeamento de reações em usinas químicas com classificação SEVESO []] (ver também Béguin, 2003).

Estamos dentro de uma unidade de produção da química fina. o produto fabricado é explosivo e pode estar em três estados. Frio, ele fica espesso e endurece, é a sobrefusão. Aquecendo, ele se torna líquido e é seu estado ideal. Mas, muito quente, ele produz um gás altamente explosivo. É o desencadeamento de reação que constitui o principal risco de acidente fatal nessa indústria química. Para recuperar a produção, os operadores podem ficar na usina até a explosão. Os engenheiros conceberam um sistema de segurança. Trata-se de um alarme cuja finalidade é predizer um "tempo médio antes da explosão" (TMR). Um algoritmo de detecção foi desenvolvido, depois testado em "situação experimental" : de fato, foi proposto, que um protótipo do artefato fosse introduzido em uma situação piloto. 0 protótipo do alarme exibiria (i) o Tempo Médio Restante - TMR e (ii) indicações precisas sobre a temperatura do produto (em centésimos de grau).

Os resultados serão eloqüentes. Eles mostrarão, inicialmente, que os operadores consultam cada vez mais freqüentemente o alarme, o que a priori é positivo. Assim, nos primeiros testes, os usuários só consultam a interface durante 1,7\% do tempo total de operação. Mas eles a consultam durante 31,5 
\% do tempo no início do quarto mês (ver tabela 1). Portanto, os operadores se apropriam do artefato. Mas uma análise mais fina das tomadas de informação (orientação do olhar) mostra, contudo, o caráter paradoxal desses resultados. Os operadores utilizam o alarme, ao invés dos termômetros anteriormente disponíveis (ver tabela 1). Assim, os operadores usam do artefato as informações de temperatura e não o TMR, que constitui o interesse do sistema. Os operadores atribuem, portanto, uma função ao protótipo bem diferente daquela concebida pelos projetistas.

Tabela 1 : Evolução comparada das durações das tomadas de informação entre o protótipo e os termômetro anteriormente disponíveis na unidade de produção (em percentual do tempo total do trabalho) entre a $1^{\mathrm{a}}, 2^{\mathrm{a}}$ e $3^{\mathrm{a}}$ sessão de testes do protótipo

\begin{tabular}{|c|c|c|c|}
\hline & $\begin{array}{l}\text { 1: Sessão de } \\
\text { testes }\end{array}$ & $\begin{array}{l}\text { 20 Sessáo de } \\
\text { testes }\end{array}$ & $\begin{array}{l}3^{2} \text { Sessão de } \\
\text { testes }\end{array}$ \\
\hline $\begin{array}{l}\text { Duraça o das tomadas } \\
\text { de informaçào no protótipo }\end{array}$ & $1,7 \%$ & $8,1 \%$ & $31,5 \%$ \\
\hline $\begin{array}{l}\text { Duraça de tomadas de informa- } \\
\text { ça nos indicadores de tempera- } \\
\text { tura anteriormente disponiveis }\end{array}$ & $27.3 \%$ & $24,5 \%$ & $4,2 \%$ \\
\hline \multicolumn{4}{|c|}{ 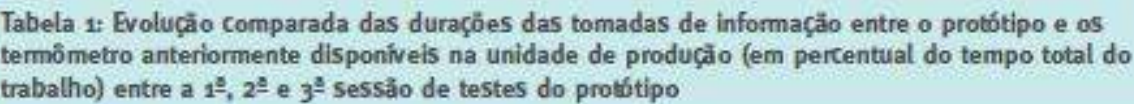 } \\
\hline
\end{tabular}

Esta evolução da função do artefato, que se efetua na atividade dos operadores, tem origem nas suas estratégias de condução do processo de produção. Na realidade, os operadores conduzem o processo mantendo a temperatura no limite mais baixo possível. É uma estratégia que "afasta" o risco maior de desencadeamento de reação (que ocorreria no limite de temperatura mais elevado). Mas a operação no frio (com temperaturas baixas) é também arriscada: se o produto tornase muito frio ele pode "cristalizar" e torna-se sólido. É o "risco cotidiano" para retomar a expressão dos operadores.

Deixando-o mais espesso, o produto pode provocar a quebra de certos materiais (que são de vidro) ; além disso, deixar o produto se reaquecer é perigoso. Ora, as informações fornecidas pelo termômetro do protótipo eram muito mais precisas que aquelas fornecidas pelos outros termômetros na unidade de produção. $O$ alarme recebeu, portanto, na atividade dos operadores, a função de uma ferramenta que apóia a condução do processo químico.

Esse status era, contudo, inaceitável para os projetistas. Por duas razões. Primeiramente, nas situações classificadas como SEVESO, uma norma européia (NE 31) impõe dissociar os "sistemas de segurança" (safety instrumented systems) das outras ferramentas. De outro lado, o dispositivo permitia de evitar o risco cotidiano de cristalização. Mas qual papel ele teria em relação ao risco maior do desencadeamento de reação que se constituía no objetivo principal do projeto ? A apropriação feita pelos operadores deixava os projetistas numa situação extremamente desconfortável. Ela sinalizava, inclusive, um fracasso. As discussões com o conjunto de atores envolvidos 
(projetistas, operadores, direção e nos mesmos) permitirão de desbloquear a situação e de conceber dois instrumentos.

Inicialmente, um conjunto de discussões foi realizado sobre a diferença de pontos de vista e de especialização entre os operadores e projetistas. Os primeiros são centrados sobre a condução do processo que repousa sobre uma especialização em cristalização, que constitui um risco menor, mas cotidiano. Os engenheiros, ao contrário são centrados sobre o risco maior e para tal eles têm uma "especialização no desencadeamento de reação". São dois mundos profissionais distintos (Béguin, 2005), mas que são todos dois legítimos. Os projetistas, portanto, notaram a inventividade dos usuários. As análises do trabalho foram realizadas para compreender as necessidades dos operadores em relação à temperatura. Conseqüentemente, o artefato foi modificado : uma visualização do histórico da temperatura sob a forma de uma curva foi adicionada além da visualização do valor instantâneo. Uma curva permite, na realidade, de interpretar a "tendência" da cinética térmica do produto, o que se revelou uma variável utilizada elos operadores para prevenir o "risco cotidiano". De outro lado, as trocas mostraram que seria impossível ficar no face a face. Certamente o risco maior de desencadeamento de reação, que serve de referência aos engenheiros, não permite a operação do processo e nem de fazer face ao risco cotidiano. Mas a cristalização, que constitui a referência dos operadores não é suficiente. Um desencadeamento de reação poderia ocorrer consecutivamente a uma pane material por exemplo. Ora para os operadores, as possibilidades de construir um conhecimento sobre o desencadeamento de reação eram concretamente inexistentes : é preciso produzir e para tal é necessário se afastar o máximo possível da temperatura alta. No caso de desencadeamento de reação, os operadores deveriam "enfrentar o desconhecido" para retomar os termos deles. Donde a idéia de conceber um instrumento que permitiria aos operadores de melhor conhecer as condições concretas do desencadeamento de reação. $O$ protótipo foi, portanto, modificado para permitir aos operadores de simular a temporalidade desses eventos maiores sobre uma usina piloto (o produto fabricado era então trocado por um líquido inerte). Três simulações são realizadas. Elas mostrarão, em duas simulações, que os operadores fracassariam devido a condições organizacionais e arquiteturais da usina. Um operador a mais foi contratado e a arquitetura da sala de controle modificada. Nesse projeto, uma primeira versão do artefato recebeu o status de hipótese instrumental. Sobre a base de sua utilização, os operadores produziram uma resposta (criativa) que modificou sua função e sua significação. Os projetistas a consideraram especificando uma visualização do histórico da temperatura sob a forma de uma curva. Mas esta resposta não fechou o diálogo. Ela gerou uma resposta dos projetistas que desenvolveram um artefato cuja finalidade era conduzir os operadores sobre sua própria situação de trabalho, oferecendo-lhes a possibilidade de experimentar as condições concretas de um desencadeamento de reação.

Esse caso coloca em evidência uma dimensão importante do dialogismo pouco evocado até aqui. Acabamos de sublinhar que a apropriação dos operadores havia colocado os projetistas numa situação extremamente desconfortável. Este desconforto só foi resolvido a partir de uma reorientação do projeto. Assim, neste exemplo, nos acordamos que não se tratava de conceber um alarme (que era inicialmente o projeto), mas de diminuir a ocorrência de acidentes maiores e equipar os atores para poder enfrentá-los. Ora, evocando a noção de "projeto" tocamos numa distinção de fundo na concepção. Conceber é realizar uma mudança concreta no contexto físico e social. Mas é fazê-lo sobre a base de uma vontade relativa ao futuro. Uma abordagem dialógica 
contribui a construir esta significação no ceio de um grupo heterogêneo de atores e não somente a especificar um instrumento.

\section{Construir a organização da concepção}

$42 \mathrm{Na}$ introdução desse texto, foi escrito que os modelos clássicos da engenharia tendem a fazer pouco caso das racionalidades, dos saberes e dos valores daqueles que usaram o objeto concebido ou o procedimento novo. Um modelo dialógico de concepção foi proposto. Sua finalidade é situar sobre a mesma cena as lógicas e posições heterogêneas dos operadores e projetistas para um fazer em comum. Uma grande parte do papel do ergonomista consiste a favorecer esta organização da ação. E, neste texto, nos focalizamos, sobretudo, a dimensão temporal. Entretanto, a organização de uma concepção dialógica não reside somente na dimensão temporal. Ela reside também nas relações de poder e nos valores mobilizados pelos atores.

Gärtner \& Wagner (1996) muito insistiram sobre o fato de que os operadores não eram considerados legítimos na concepção. Zarifian (1996) colocou em evidência, de forma justa, que os saberes dos operadores nem sempre interessavam aos projetistas. $\mathrm{Na}$ medida em que a concepção se caracteriza por uma heterogeneidade e uma polissemia, os atores da concepção podem legitimamente estar em desacordo. Mas estas divergências entre os atores podem ser tratadas segundo duas vias contrárias.

- Uma primeira via é o conflito, por exemplo, a autoridade ou a exclusão de certos atores cuja finalidade ou os critérios aparecem como sendo muito divergentes ou não significativos.

- A segunda via é justamente a concepção : modificam-se as características do objeto em curso de concepção, mudam-se os critérios, redefinem-se as finalidades para que a solução seja aceitável por todos.

O que distingue os dois é que no conflito, resolvem-se os desacordos através de uma face a face entre os atores: o mais forte ganha. Na concepção, ao contrário, é à complexidade do real que se atribui a dificuldade das trocas. Entre os dois se opera uma reversão. No primeiro caso, resolvem-se as dificuldades suprimindo a diversidade de pontos de vista no interior do grupo e a complexidade do real passa a um segundo plano. No segundo, concebe-se justamente porque se procura resolver as dificuldades se arranjando diante dos fatos, mas respeitando a diversidade de pontos de vista no interior do grupo.

Ora, entre os dois regimes coloca-se a questão das relações entre saber e poder. Foucault (2004) que bastante insistiu, apontou uma distinção entre duas formas de "dispositivos": dispositivos "normativos" e dispositivos de "normalização". Os "normativos" se caracterizam pelo fato de que os saberes se transformam em poder. Os segundos dispositivos de "normalização" consistem a construir curvas de desenvolvimentos dos saberes para instituir localmente a normalidade. Observando bem, as proposições feitas nesse texto têm por finalidade orientar a concepção no sentido menos normativo, a fim de instituir localmente a normalidade graças a formas dialógicas de concepção. Pode-se, inclusive, argumentar que tal abordagem é igualmente favorável à saúde dos trabalhadores. Canguilhem (1966), em efeito, nos explicou que o "O homem saudável" é aquele que não sofre as limitações do meio ambiente, mas, é capaz de modificá-las para afirmar suas normas (por exemplo, normas profissionais) e seu projeto de vida. 
Mas os dispositivos "normativo" e de "normalização" são dois quadros sócio-cognitivos em grande parte desenvolvidos. A intervenção em ergonomia se inscreve de fato num contexto social que a precede $\left[{ }^{10}\right]$. Em nenhum caso seu papel é neutro. Compartilhamos a posição de Daniellou \& Garrigou: o ergonomista tem um papel muito ativo de reenquadramento das trocas, ele é mesmo, nos parece, um vigia deste enquadramento. Mas tal formulação enfatiza, também, a importância de ver claramente as dimensões sociais e axiológicas (os valores) do enquadramento. Essas duas dimensões constituem um plano de fundo incontornável da concepção sendo, até mesmo, uma condição do dialogismo que torna urgente compreender a gramática e a gênese durante a condução do projeto.

\section{BIBLIOGRAFIA}

Bannon, L. (1986). Issues in design : some notes. In D.A. Norman \& S.W. Draper (Eds.), Usercentered system design (pp. 25-30). Hillsdale, NJ : LEA.

Bakhtin, M. (1970). La poétique de Dostoïevski. Paris : Points Seuil.

Béguin P. (1993, septembre). Field evaluation and collective work design in practice with CAD. Workshop on evaluation studies in CSCW, ECSCW'93. Milan, Italy.

Béguin, P. (1994). De l'individuel au collectif dans les activités avec instruments. Thèse de Doctorat, CNAM, Paris.

Béguin, P. (1997). Le schème impossible, ou l'histoire d'une conception malheureuse. International Journal of Design and Innovation Research, 10, 21-39.

Béguin, P. (2003). Design as a mutual learning process between users and designers. Interacting with Computers. 15/5, 709-730.

Béguin, P. (2005). Concevoir pour les genèses professionnelles. In P. Rabardel \& P. Pastré (Coords.), Modèles du sujet pour la conception, dialectiques activités développements (pp. 31-52). Toulouse : Octarès.

Béguin, P. (2007a). Dialogisme et Conception des Systèmes de Travail. Psychologie de l'Interaction, 23/24, 169-198.

Béguin, P. (2007b). Taking activity into account during the design process. @ctivités, 4, (2), 115-121. http://www.activites.org/v4n2/v4n2.pdf .

Béguin, P. \& Clot, Y. (2004). L'action située dans le développement de l'activité. @ctivités, 1, (2), 27-49. http://www.activites.org/v1n2/beguin.fr.pdf

Béguin, P., Millanvoye, M. \& Cottura, R. (1998). Analyse ergonomique dans un atelier de mise sous pli. (Rapport de recherche). Document du Laboratoire d'Ergonomie et Neurosciences du Travail, CNAM.

Béguin, P. \& Rabardel, P. (2000). Concevoir pour les activités instrumentées. Recherche en Intelligence Artificielle, 14, 35-54. 
Béguin, P. \& Weill-Fassina, A. (coords.) (1997). La simulation en Ergonomie : connaître, agir, interagir. Toulouse : Octarès.

Bjerknes, G. \& Bratteteig, T. (1987). Florence in wonderland. In G. Bjerknes, P. Ehn \& M. Kyng (Eds.), Computer and democracy - a scandinavian challenge (pp. 279-295). Aveburry : Aldershot.

Bjerknes, G. \& Bratteteig, T. (1995). User participation and democracy. A discussion of scandinavian research on system development. Scandinavian Journal of information systems, 7, (1), 25-45.

Bucciarelli, L.L. (1994). Designing Engineers. Cambridge : The MIT Press.

Bødker, S. \& Grønboek, K. (1996). Users and designers in mutual activity : an analysis of cooperative activities in systems design. In Y. Engeström \& D. Middleton (Eds.), Cognition and communication at work (pp. 130-158).Cambridge : University Press.

Canguilhem, G. (1966). Le normal et le pathologique. Paris : PUF.

Caroll, J. (1991). The little kittle little house. In J. Caroll (Ed.), Designing interaction : Psychology at the Human Computer Interface (pp. 3754). Cambridge : University Press.

Clot, Y. (1999). La fonction psychologique du travail. Paris : PUF.

Daniellou, F., Laville, A. \& Teiger, C. (1983). Fiction et réalité du travail ouvrier. Cahiers Français de la Documentation Pédagogique, 209, Jan./Fév., 39-45.

Daniellou, F. (1992). Le statut de la pratique et des connaissances dans l'intervention ergonomique de conception. Thèse d'habilitation à diriger des recherches, Université de Toulouse-Le Mirail, Toulouse.

Daniellou, F. (2007). A ergonomia na condução de projetos de concepção de sistema de trabalho. In P. Falzon (Ed.), Ergonomia (pp. 303-316). São Paulo : Editoria Blucher.

Daniellou, F. \& Garrigou, A. (1993). La mise en oeuvre des représentations des situations passées et des situations futures dans la participation des opérateurs à la conception. In D. Dubois, P. Rabardel \& A. Weil-Fassina (Coords.), Représentations pour l'action (pp. 295-309). Toulouse : Octares.

Duarte, F., Lima, F., Remiro, R. \& Castro Maia, N. (2008, septembre). Situations d'action caractéristiques et configuration d'usage pour la conception. 43éme Congrès de la SELF, Ajaccio, Corsica.

Easterbrook, S.M., Beck, E.E., Goodlet, J.S. \& Plowman, L. (1993). A survey of empirical studies of conflict. In : S.M. Easterbrook (Ed.), C.S.C.W. cooperative or conflict (pp. 1-68). Berlin : Springer Verlag. Ellul, J. (1977). Le Système technicien. Paris : Calmann-Lévy.

Cole, M. (1996). Cultural Psychology : Once and Future Discipline ? Cambridge : Harvard University Press.

Foucault, M. (2004). Sécurité, Territoire, Population. Cours au Collège de France, 1977-1978. Paris : Gallimard/Seuil.

Garrigou, A., Thibault, J. F., Jackson, M., \& Mascia, F. (2001). Contributions et démarche de l'ergonomie dans les processus de conception. Pistes, 3, 2. http://www.pistes.uqam.ca/v3n2/ articles/v3n2a6.htm

Gärtner, J. \& Wagner, I. (1996). Mapping actors and agendas : political frameworks of systems design and participation. HumanComputer Interaction, 11, (3), 187-214. 
Gerson, E., \& Star, S. (1986). Analysing Due process in the work place. ACM Transactions on office information systems, 4/3, 265-287.

Geslin, Ph. (1999). L'apprentissage des mondes. Une anthropologie appliquée aux transferts de technologies. Paris : Editions de la Maison des sciences de l'homme.

Guérin F., Laville, T., Daniellou, F., Durrafourg, J. \& Kerguelen, A. (1997). Comprendre le travail pour le transformer, la pratique de l'Ergonomie. Lyon : ANACT.

Hatchuel, A. (1996). Coopération et conception collective. Variété et crises des rapports de prescription. In G. de Terssac \& E. Friedberg (Eds.), Coopération et conception (pp. 101-122). Toulouse : Octarès.

Hammer, M. \& Champy, J. (1993). Reengineering the corporation. New York : Harper Collins Business.

Henderson, A. \& Kyng, M. (1991). There is no place like home. Continuing design in use. In J. Greenbaum and M. Kyng (Eds), Design at Work, Cooperative Design of Computer Systems (pp. 145-167). Hillsdale : Lawrence Erlbaum.

Joas, H., (1999). La créativité de l'agir. Paris : Les éditions du Cerf.

Keyser (de), V. (1988). De la contingence à la complexité. L'évolution des idées dans l'étude des processus continus. Le Travail Humain, 51, 1-18.

Leontiev, A. (1976). Le développement du psychisme. Paris : Editions Sociales.

Leplat, J. (2000). L'analyse psychologique du travail en ergonomie. Toulouse : Octarès.

Mackay, W. (1988). More than just a communication system : diversity in the use of electronic mail. Working paper (Sloan school of management, MIT).

Maline J. (1994). Simuler le travail, une aide à la conduite de projet. Paris : ANACT.

Malone, T.W., Grant, K.R. \& Turbak, F. (1986). The information LENS : an intelligent system for information sharing and organizations. In Proceedings of the $\mathrm{CHI} 86$ conference on human factors in computing systems (pp. 1-8). New York : ACM.

Mer, S., Jantet, A. \& Tichkievitch, S. (1995). Les objets intermédiaires de la conception, modélisation et coordination. In Caelen J. \& Zreik K. (Eds.), Le communicationnel pour concevoir. Paris : EuropIA Productions.

Midler, C. (1993). Situation de conception et apprentissage collectif. In R. Benedicte (Dir.), Les limites de la rationnalité, Tome 2 : Les figures du collectif (pp. 169-180). Paris : Ed. La Découverte.

Montmollin, M. de, (1992). Macroergonomics : hodge podge or new foundation. Le travail humain, 55, (2), 112-125.

Moran, T. \& Caroll, J. (1996). Design rationale. London : Lawrence Erlbaum.

Nicolas, L., (2000). L'activité de conception durant l'analyse fonctionelle : vers des outils anthropocentrés pour la conception de produits automobiles. Doctorat d'Ergonomie, CNAM, Paris.

Perrin, J. (1983). Les transferts de technologie. Paris : Editions La découverte, Collection repères.

Rabardel, P. \& Beguin, P. (1995). L'utilisation des fichiers CAO par les concepteurs comme outil de gestion du projet et d'organisation de leur activité. In K. Zreik and B. Trousse (Eds.), Organisation de la Conception (pp. 141-151). Paris : EUROPIA. 
Rabardel, P. \& Béguin, P. (2005). Instrument Mediated Activity : from Subject Development to Anthropocentric Design. Theoricals Issues In Ergonomics Science, 6, (5), 429-461.

Randell, R. (2003). User customisation of medical devices : the reality and the possibilities. Cogn Tech Work, 5, 163-170.

Rasmussen, J. (2000). Human Factors in a Dynamic Information Society : Where are we Heading? Ergonomics, 43, 7, 869-879.

Robinson, M. (1993). Design for unanticipated use. In D. Michelis, C. Simone \& K. Schmidt (Eds.), Proceedings of the third European conference on C.S.C.W (pp. 187-202). Dordrecht : Kluwer Academic Press.

Schwartz, Y. (2000). Discipline épistémique, discipline ergologique. Paideia et Politeia. In B. Maggi (Ed.), Manière de penser, manières d'agir en éducation et en formation (pp. 33-68). Paris : PUF.

Schön, D. (1983). The reflective practitioner. How professionals think in action. New York : Harper Collins Publisher.

Simondon, G. (1958). Du mode d'existence des objets techniques. Paris : Aubier.

Weill-Fassina, A., Rabardel, P. \& Dubois, D. (coords.)(1993). Représentation pour l'action. Toulouse : Octarés.

Wertsch, J.(1998). Mind as action. Oxford : University Press.

Wisner, A. (1972). Diagnosis in ergonomics or the choice of operating models in field research. Ergonomics, 15, (6), 601-620.

Wisner, A. (1995). Understanding problem building : Ergonomic Work Analysis. Ergonomics, 38, (8), 1542-1583.

Zarifian, P. (1996). Travail et communication. Essai sociologique sur le travail dans la grande entreprise industrielle. Paris : PUF.

\section{NOTAS}

1. É feito aqui referência à introdução do livro «as ações não saberiam ser reduzidas a respostas efetiva aos estímulos recebidos, mais ou menos passivamente, a atos motores, a procedimentos de execução. Elas manifestam nos fatos, os processos pelos quais os operadores exploram, interpretam, utilizam, transformam seu ambiente técnico, social, e cultural» (Weill-Fassina, Rabardel \& Dubois, 1993, p.21).

2. Ver Joas (1999) para uma apresentação teórica bastante documentada sobre a criatividade situada do agir e Wisner (1995) para uma argumentação no campo da ergonomia.

3. Leplat (2000) propôs um modelo simples, mas eficiente, no qual a atividade é função da relação entre tarefa e sujeito. É esta tal ligação, entre o artefato e as formas de ação que está em jogo aqui.

4. Este individualismo coloca, evidentemente, um problema que não é somente conceitual. Podese, entretanto, sublinhar que existem mundos profissionais (Béguin, 2005) que definem invariantes culturais da ação. Este ponto não será tratado neste artigo.

5. Ver Béguin (2007a) para uma apresentação mais detalhada.

6. O objetivo não é dizer que não há diferença entre a concepção e a comunicação. Em revanche, pode-se pensar que a linguagem, forma dominante do dialogismo não é a única forma possível. A concepção pode conhecer outras formas de dialogismo, na condição de se pensar nas suas especificidades. 
7. O termo cristalização utilizado anteriormente considera este fato.

8. Esta organização da ação é muito próxima do que Schön (1983) descreve como um "diálogo com a situação". Inicialmente, o projetista desenhista projeta as idéias novas a partir dos saberes anteriormente construídos, mas a simulação mental que ele realiza lhe revela resistências, fonte de ajustes.

9. A classificação SEVESO é uma classificação de risco adotada na Europa.

10. Trata-se, em realidade, de uma dimensão que se impõe ao ergonomista e que é certamente mais importante quanto mais nos encontramos em setores de baixo valor agregado e com operadores de baixo nível de qualificação.

\section{RESUMOS}

A ergonomia da atividade tem, já há muito tempo, evidenciado a inventividade dos operadores nas situações industriais. Na concepção, esta posição abre um novo campo: sobre qual base articular concepção no trabalho e trabalho de concepção? Neste artigo, são discutidas as razões pelas quais a concepção continua durante o uso. Sobre esta base se argumenta que a concepção é um processo de desenvolvimento conjunto do artefato e da forma de ação. É, justamente, esse encontro entre artefato e ação, aqui definido como "instrumento", que é necessário conceber. Sobre essa base conceitual, é proposto um modelo dialógico da concepção. A partir da "hipótese instrumental" oriunda desse modelo, são propostas e ilustradas diferentes vias de organização do processo de concepção.

La ergonomía de la actividad, hace ya mucho tiempo, ha evidenciado la inventividad de los operadores en las situaciones industriales. En la concepción, esta posición abre un nuevo campo : sobre ¿qué base articular concepción en el trabajo y trabajo de concepción? En este artículo, se discuten las razones por las cuales la concepción sigue durante el uso. Sobre esta base se argumenta que la concepción es un proceso de desarrollo conjunto del artefacto y de la forma de acción. Es, justo, ese encuentro entre artefacto y acción, aquí definido como "instrumento", que es necesario concebir. Sobre esa base conceptual, se propone un modelo dialógico de la concepción. A partir de la "hipótesis instrumental" oriunda de ese modelo, se proponen y se ilustran diferentes vías de organización del proceso de concepción.

L'ergonomie de l'activité a depuis longtemps pris à bras-le-corps la question de l'inventivité dont témoignent les opérateurs dans les situations industrieuses. Mais dans la conception, cette position ouvre un chantier: sur quelle base articuler conception dans le travail et travail de conception? Dans cet article, on discute les raisons pour lesquelles la conception se continue dans l'usage. Sur cette base, on argumente que la conception est un processus de développement conjoint de l'artefact et de forme de l'action. C'est le couplage entre les deux qu'il faut concevoir, couplage qu'on défini comme un “instrument». Et sur cette base, on propose un modèle dialogique de la conception. A partir de la notion "d'hypothèse instrumentale", issue de ce modèle, on propose et on illustre différentes voies d'organisation de la conception.

For a long time now, the activity-centered approach to ergonomics has been showing operators' inventiveness in industrial situations. In terms of design, this position opens up a new field: on which grounds can one articulate 'design at work' and 'the work of design'? In this paper, the reasons why designing continues during use are discussed. Against this background it is argued 
that design is a development process encompassing both the artifact and the way it is used (the form of action). It is precisely that coming together of artifact and use, here defined as 'instrument', which is necessary for design. On this conceptual basis, a dialogical model of design is proposed. From this model's 'instrumental hypothesis', different forms of organizing the design process are proposed and illustration is provided.

\section{ÍNDICE}

Palavras-chave: atividade de trabalho, inovação, instrumento, dialogismo, projeto

Keywords: work activity, innovation, dialogism, project

Mots-clés: activité de travail, innovation, instrument, dialogisme, projet

Palabras claves: actividad de trabajo, innovación, instrumento, dialogismo, proyecto

\section{AUTORES}

\section{PASCAL BÉGUIN}

Institut National de la Recherche Agronomique, 147 rue de l'université, 75338 Paris Cedex 07,

France

pbeguin@grignon.inra.fr 